\title{
Agricultura familiar: importância e dificuldades da inserção na alimentação escolar na microrregião de Picos - PI
}

Family agriculture: importance and difficulties of insertion in school in the Picos

\author{
microregion - PI \\ Sintia Andrea Barbosa Gomes ${ }^{1}$ \\ Nutricionista, Universidade Federal do Piauí (UFPI), Campus Picos \\ E-mail: sintiaandrea@hotmail.com \\ Laerte Bezerra de Amorim ${ }^{2}$ \\ Prof. Dr. Instituto de Educação, Ciência e Tecnologia do Piauí, IFPI \\ E-mail:laerte@ifpi.edu.br
}

\begin{abstract}
Resumo: Objetivou-se destacar a importância e as dificuldades da inserção de gêneros alimentícios provenientes da agricultura familiar na alimentação escolar por meio de um estudo transversal descritivo, cujos dados foram obtidos no período no segundo semestre de 2015 nos 20 municípios que compõem a microrregião de Picos, PI. Um questionário composto por perguntas objetivas e subjetivas foi apresentado ao Nutricionista responsável pelo Programa Nacional de Alimentação Escolar (PNAE) ou na ausência do mesmo, ao secretário(a) de educação na Secretaria Municipal de Educação e/ou no Setor de Alimentação Escolar dos municípios, após a concordância dos mesmos. Dezenove municípios estão inseridos no Programa e três dos vinte municípios não atingiram a meta de $30 \%$ de gêneros provenientes da agricultura familiar, sendo destacados como fatores que justificam esse dado: a deficiência em relação às infraestruturas para a produção, armazenamento e a distribuição desses produtos, a falta de conhecimento por parte do agricultor quanto ao funcionamento do PNAE, a falta da documentação exigida pelo programa, condições climáticas e quantidade insuficiente de gêneros disponíveis para a venda. Diante dos dados observados ressalta-se a importância do PNAE como estratégia de promoção de saúde no ambiente escolar. Nesse sentido, foi perceptível a necessidade de maior incentivo e conscientização de gestores, profissionais de saúde, agricultores e comunidade na acepção de favorecer a agricultura familiar dentro do contexto da alimentação do escolar.
\end{abstract}

Palavras-chave: Programa Nacional de Alimentação Escolar; Segurança Alimentar e Nutricional; Saúde escolar.

Abstract: The objective of this study was to highlight the importance and difficulties of the insertion of foodstuffs from family farms in school feeding through a descriptive cross-sectional study whose data were obtained during the second half of 2015 in the 20 municipalities that make up the micro-region of Picos, PI. A questionnaire composed of objective and subjective questions was presented to the Nutritionist responsible for the National School Feeding Program (PNAE) or in the absence thereof, to the secretary of education at the Municipal Department of Education and / or the School Feeding Sector of the municipalities, After their agreement. Nineteen municipalities are included in the Program and three of the twenty municipalities have not reached the goal of $30 \%$ of the genera from family agriculture, and are highlighted as factors that justify this: deficiency in infrastructure for the production, storage and distribution of these products, The lack of knowledge on the part of the farmer about the functioning of the PNAE, the lack of 
documentation required by the program, climatic conditions and insufficient quantity of available genera for sale. In view of the observed data, the importance of PNAE as a strategy for health promotion in the school environment is highlighted. In this sense, the need for greater incentive and awareness of managers, health professionals, farmers and the community in the sense of favoring family farming within the context of school feeding was perceptible.

Keywords: National Program of School Feeding; Food and Nutrition Security; School health.

\section{Introdução}

O Programa Nacional de Alimentação Escolar (PNAE) é uma política governamental, de âmbito nacional, que visa a suprir, no mínimo, 20\% das necessidades nutricionais dos escolares durante a permanência em período parcial na escola, objetiva, ainda, contribuir para a redução dos índices de evasão escolar, para a formação de bons hábitos alimentares e para o aumento da capacidade de aprendizagem (FLÁVIO et al., 2008).

O orçamento do Programa dotado em 2017 de R \$ 4,15 bilhões (FNDE, 2017a), em que 30\% ( $\mathrm{R} \$ 1,24$ bilhões) deve valor será investido na compra direta de produtos da agricultura familiar de acordo com o exigido na Lei $n^{\circ}$ 11.947, de 16/6/2009 (BRASIL, 2009a). Essa exigência contribui para desenvolvimento e crescimento econômico sustentável das comunidades produtoras de alimentos para o PNAE (RODRIGUES et al. 2017), além de incentivar aos produtores da agricultura familiar local o aumento da quantidade e da diversidade de alimentos e garantir a compra de seus produtos.

A introdução de gêneros alimentícios provenientes da agricultura familiar possibilita aos municípios utilizar alimentos mais saudáveis, sendo priorizados os orgânicos e ou agroecológicos. O intuito é aumentar a qualidade das refeições servidas, possibilitando o desenvolvimento da agricultura familiar e incentivar à economia local (BRASIL, 2009b; CHAVES et al., 2009).

A agricultura familiar vive, dentre tantos outros desafios, o de ampliar a produção de alimentos (RODRIGUES et al., 2017) que passa por vários problemas como a diminuição da população camponesa prioritariamente da juventude rural, em busca de avançar na escolaridade e ou de novas oportunidades de trabalho; as questões climáticas; a fragilização da assistência técnica e extensão rural; a escassez de crédito apropriado e acessível; dentre outros percalços (AROUCHA, 2012). 
A agricultura familiar sempre foi marginalizada e, em algumas regiões, como no sertão e no semiárido nordestino, os próprios agricultores têm problemas de geração de renda capaz de contemplar as necessidades mínimas (KAGEYAMA; HOFFMANN, 2007). Produzir mais, por mais períodos em todo ano, e com regularidade, é uma condição indispensável que passa a ser não apenas mais um, mas o maior desafio objetivo para agricultura familiar, além de estar diretamente associado a outro, que é a situação de fragilidade muito comum de parte das Organizações Produtivas da Agricultura Familiar (OPAF), que não estão devidamente organizadas e habilitadas para atender a todas as Chamadas Públicas de Compras (CPC), das Secretarias de Educação Estaduais (SEEs) e das Secretarias Municipais de Educação (SMEs), com recursos federais repassados pelo Fundo Nacional de Desenvolvimento da Educação (FNDE), através do PNAE (AROUCHA, 2012).

O nordeste, principalmente, o Piauí, é uma região castigada pela seca e com dificuldades no desenvolvimento da agricultura familiar, nesse contexto a microrregião de Picos, envolvendo 20 municípios, foi escolhida para a realização dessa pesquisa que objetiva destacar a importância e as dificuldades da inserção de gêneros alimentícios provenientes da agricultura familiar na alimentação escolar, demonstrando as dificuldades encontradas tanto pelo órgão municipal para a aquisição, como pelos produtores para produzir e distribuir esses alimentos nas escolas, a fim de destacar a importância na utilização de alimentos fornecidos pela produção familiar, de preferência local, como também a importância de que esses municípios atinjam a meta primária de $30 \%$ dos repasses federais do PNAE, como preconiza o FNDE.

\section{Metodologia}

O estudo foi realizado de forma transversal descritiva em que os dados foram obtidos através de um questionário com 12 perguntas, objetivas e subjetivas, apresentado ao Nutricionista responsável pelo Programa Nacional de Alimentação Escolar (PNAE). $\mathrm{Na}$ ausência do mesmo, o questionário foi aplicado ao secretário (a) de educação na Secretaria Municipal de Educação e/ou no Setor de Alimentação Escolar dos municípios, os mesmos responderam às entrevistas após a leitura e concordância do Termo de Consentimento, neste caso na forma de ofício. A coleta de dados foi realizada no período de setembro a novembro de 2015. 
O questionário foi formulado pelos autores desse estudo com auxílio das dúvidas mais frequentes dos nutricionistas em relação à compra de gêneros para alimentação escolar provenientes da agricultura familiar regional destacadas no site do FNDE.

O estudo foi direcionado para os 20 municípios que formam a microrregião de Picos-PI, os quais são eles: Aroeira do Itaim, Bocaina, Cajazeiras do Piauí, Santa Cruz do Piauí, Santa Rosa do Piauí, Picos, Oeiras, Paquetá, Ipiranga do Piauí, Dom Expedito Lopes, Wall Ferraz, Sussuapara, São José do Piauí, São Luís do Piauí, Santana do Piauí, Colônia do Piauí, Geminiano, São João da Canabrava, São João da Varjota e Tanque do Piauí. Segundo o FNDE, o exercício de 2015 possuía 34.503 alunos cadastrados e beneficiados pelo PNAE nos 20 municípios (FNDE, 2017b). Para preservação do sigilo em relação aos municípios entrevistados, os mesmos foram identificados com letras do alfabeto (A a T). Os dados foram tabulados no programa Microsoft Excel ${ }^{\circledR} 2010$.

A pesquisa obedeceu aos princípios de Resolução $\mathrm{N}^{\circ} 466$, de 12 de dezembro 2012, que resolve sob a ótica do indivíduo e das coletividades, referenciais da bioética, tais como, autonomia, não maleficência, beneficência, justiça e equidade, dentre outros, e visa a assegurar os direitos e deveres que dizem respeito aos participantes da pesquisa, à comunidade científica e ao Estado.

\section{Resultados e Discussão}

Todos os municípios avaliados estão inseridos no PNAE, sendo que 19 (dezenove) deles utilizam gêneros da agricultura familiar de sua região, enquanto um não faz uso de alimentos provenientes da agricultura local. Dos 20 municípios da microrregião de Picos, 17 conseguem atingir a meta dos $30 \%$ de gêneros alimentícios dentro das escolas e às vezes até mais que esse percentual.

A problemática de ainda existir municípios que não conseguem atingir o percentual mínimo de alimentos exigidos na lei do programa da alimentação escolar é bastante preocupante, conforme o artigo 37 da Resolução CD/FNDE n 38, de 16 de julho de 2009 (BRASIL, 2009b), o FNDE suspenderá o repasse dos recursos financeiros à conta do PNAE quando a Entidade Executora (município) não aplicar os recursos em conformidade com os critérios estabelecidos. Isso implica, que os três municípios (15\%) que não cumpriram a Lei da agricultura familiar (BRASIL 2009a), sofreram suspensão da verba do PNAE ou tiveram que se explicar para o Ministério da Educação/PNAE. Caso tenha ocorrido a suspensão nesses municípios, os alunos podem ter ficado com uma alimentação inferior ao que preconiza o PNAE ou até mesmo sem a alimentação escolar. 
Sobre o tipo de alimento fornecido na merenda escolar, é importante ressaltar que o consumo in natura de frutas e verduras podem estar inferior ao exigido pelo o PNAE, por outro lado, pode estar havendo um consumo demasiado de produtos elaborados ou semielaborados que contêm conservantes e outros aditivos, tais produtos poderiam ser evitados o consumo caso houvesse produtos in natura disponível.

Entre as dificuldades encontradas pelos os municípios para atingir a meta do PNAE, os entrevistados apontaram a 'quantidade insuficiente de gênero alimentício para a demanda solicitada' como a principal barreira. Sessenta por cento dos entrevistados, afirmaram que os alimentos produzidos no seu respectivo município são insuficientes e pouco diversificado para abastecer as escolas. Outro fator ponderável em relação à compra dos gêneros é a falta de interesse dos agricultores em que 50\% dos municípios alegaram que esse fato dificulta o processo de compra e venda. A dificuldade em apresentar a documentação exigida pelo programa foi citada como um problema em $45 \%$ dos municípios, enquanto a falta de informação dos agricultores em relação ao PNAE foi considerada um entrave na compra dos alimentos em 35\% dos municípios. De acordo com a figura 1 podemos visualizar o número de munícipios que possuem uma ou mais dificuldades para adquirir os gêneros alimentícios para serem usados na merenda escolar.

Figura 1 - Dificuldades encontradas pelos municípios na compra de gêneros alimentícios da região.

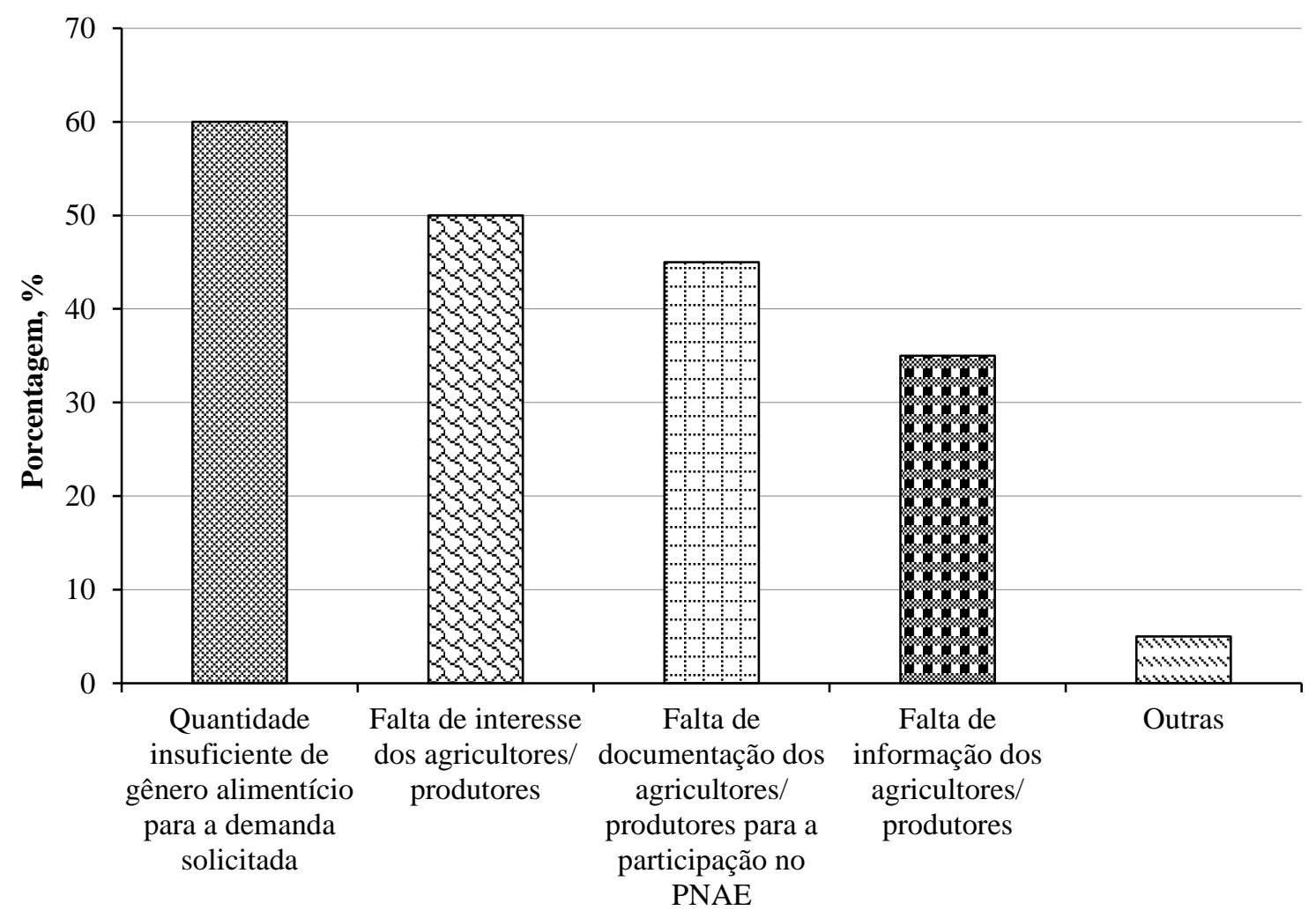


Um município, que corresponde a 5\%, apontou 'outros problemas', especificamente, a não utilização de gêneros alimentícios provenientes da agricultura familiar local (Figura 1). Segundo o entrevistado, esse fato ocorre por problemas burocráticos na administração municipal, como a ausência de chamada pública que culmina na impossibilidade do processo de compra. É importante frisar que o monitoramento da compra feito pelo FNDE é realizado na prestação de contas, conforme o artigo 36 da Resolução CD/FNDE n 38/2009 (BRASIL, 2009b).

Quando perguntado se existe grande procura por parte dos agricultores com interesse em participar do PNAE, 70\% responderam que os agricultores não tinham interesse em participar de chamadas públicas. Esse fato pode ser devido à falta de divulgação eficiente do processo de aquisição dos produtos por tal programa (RODRIGUES et al., 2017), como também o desinteresse ou a falta de confiança dos agricultores, mediante pagamentos atrasados e abaixo do valor de mercado.

A deficiência em relação às infraestruturas existentes para a produção, o armazenamento e a distribuição até o mercado consumidor é outro fator que dificulta o bom funcionamento do programa, tal fato foi bastante destacado nos questionários. A falta de conhecimento por parte do agricultor quanto ao funcionamento do PNAE também enfatiza o pequeno rol de produtores que fornecem produtos ao programa. Esses pontos demonstram claramente a ineficiência da divulgação do programa, por parte dos municípios, entraves também observados em outras regiões do Brasil (AROUCHA, 2012; RODRIGUES et al., 2017).

A falta da documentação exigida pelo programa e quantidade insuficiente de gêneros disponíveis para a venda, são outros gargalos para a consolidação do programa em alguns municípios e a expansão em outros.

Em relação às entidades articuladoras que possam facilitar o processo de compra e venda dos produtos provenientes da agricultura familiar temos Sistema Brasileiro Descentralizado de Assistência Técnica e Extensão Rural (Sibrater); Sindicatos dos Trabalhadores Rurais (STR); Sindicato dos Trabalhadores na Agricultura Familiar (Sintraf), entidades credenciadas pelo Ministério de Desenvolvimento Agrário - MDA e o EMATER (Instituto de Assistência Técnica e Extensão Rural). Nos municípios avaliados, 7 (sete) afirmaram desconhecer tais entidades, 5 (cinco) afirmaram que tiveram como mediador nesse processo o Sindicato de Trabalhadores Rurais (STR) e os demais municípios destacaram a presença do EMATER como emissor da Declaração de Aptidão 
ao Pronaf (DAP), documento necessário para o fornecimento de alimento da agricultura familiar ao PNAE.

Ao responderem sobre as vantagens da aquisição de alimentos da agricultura familiar, os entrevistados destacaram a importância do programa, tanto para os agricultores, por aumentar sua produção e gerar renda, quanto para os alunos que são beneficiados com alimentos mais saudáveis, levando em consideração hábitos alimentares e a cultura local. Além de estimular uma alimentação mais variada nas escolas e possibilitar o desenvolvimento social das famílias, sobretudo, aquelas mais carentes.

No intuito de enfatizar a formação de hábitos alimentares saudáveis, o PNAE propõe, em sua base legal, alguns princípios, dentre eles o respeito aos hábitos alimentares saudáveis, como as práticas tradicionais que fazem parte da cultura e da preferência alimentar local (CHAVES et al., 2009).

Sobre os desafios encontrados, foi relatado que a falta de inspeção sanitária para certificação dos produtos de origem animal pode ser um fator que limita o número de agricultores familiares aptos a fornecerem produtos de origem animal para a alimentação escolar. Destacou-se também, entre as respostas, as condições climáticas de toda a microrregião que possui um "clima quente e seco", há escassez de chuvas, falta de poços e de irrigação. Esses fatores somados ou de forma isolada interferem no plantio e podem ser o indicio da justificativa pela pequena produção e variedade de alimentos de cada município.

A maioria dos entrevistados afirmaram que um grande entrave é a falta de condições estruturais dos agricultores em distribuir seus produtos, pois os municípios exigem que o mesmo transporte os alimentos comprados até as escolas.

De acordo com informações do FNDE não existe uma lista fixa de produtos para a compra de alimentos da agricultura familiar, pode-se comprar qualquer tipo de gênero alimentício (in natura ou processado) desde que seja produzido pela agricultura familiar. Foi observado que cada município pesquisado, apesar de fazer parte da mesma microrregião, possui sua particularidade em relação aos seus gêneros, como destacado na tabela 1. Em todas os munícipios foi deixado bem claro que a maioria dos gêneros, principalmente as frutas, não são fornecidos o ano inteiro devido a sazonalidade das safras, podendo ser substituídas por outras que estejam na época de colheita. 
Tabela 1 - Relação dos gêneros adquiridos através do programa de agricultura familiar nos municípios da microrregião de Picos, PI, 2015.

\begin{tabular}{lclclc}
\hline Gêneros & $\mathbf{N}^{\mathbf{0}}$ de Municípios & Gêneros & $\mathbf{N}^{\mathbf{0}}$ de Municípios & Gêneros & $\mathbf{N}^{\mathbf{0}}$ de Municípios \\
\hline Abacaxi & 2 & Abóbora & 13 & Pimentão & 11 \\
Acerola & 8 & Alface & 6 & Pimentinha & 1 \\
Banana & 8 & Batata & 2 & Tomate & 12 \\
Caju & 5 & Batata doce & 5 & Fava & 1 \\
Goiaba & 9 & Beterraba & 2 & Frango & 3 \\
Laranja & 2 & Cebola & 6 & Galinha & 1 \\
Maçã & 1 & Cenoura & 3 & Goma & 1 \\
Mamão & 5 & Cheiro verde & & Pão caseiro & 1 \\
Manga & 5 & (coentro) & & Peta & 1 \\
Maracujá & 4 & Macaxeira & 10 & Polpa de frutas & 3 \\
Melancia & 14 & Milho & 1 & Sequilho & 1 \\
Melão & 2 & Pepino & 1 & & \\
\hline
\end{tabular}

Observa-se na tabela 1 um destaque na compra de melancia, onde 14 municípios têm essa fruta introduzida na alimentação escolar dos alunos contemplados pelo programa. Como justificativa podemos supor a facilidade de produção dessa fruta com um menor custo em relação a outras hortaliças na microrregião de Picos, PI. Não obstante, a abóbora (jerimum) é bastante utilizada na região nordeste do Brasil (RESENDE et al., 2013) com um consumo per capita de $1,24 \mathrm{~kg}$ e quando observado apenas o estado do Piauí, o consumo médio é de 2,62 kg por pessoa por ano (IBGE, 2010).

O consumo de cheiro verde na grande maioria dos municípios estudados pode ser justificado pela facilidade de cultivo e a possibilidade de produzir o ano inteiro, enquanto o de tomate pode ser facilmente comprado da $\mathrm{AF}$ de municípios vizinho da microrregião Picos, PI. Haja vista que essa prática é permitida quando não há a disponibilidade do item alimentício no munícipio comprador.

A aquisição de produtos semielaborados, sem a adição de conservantes ou acidulantes, como, por exemplo, pão caseiro, peta, polpa de frutas e sequilhos, são considerados alimentos da agricultura familiar, mesmo não sendo produtos in natura. É importante esclarecer que os produtos "in natura", sem nenhum tipo de processamento e de origem vegetal, não necessitam de avaliação sanitária. Já os produtos de origem vegetal que passaram por algum tipo de processamento devem ser analisados pelo Ministério da Saúde, através da Agência Nacional de Vigilância Sanitária e suas instâncias em âmbito estadual, regional e municipal (FNDE, 2015). 
Uma alimentação que respeite a identidade cultural-alimentar é fundamental para manter ou resgatar as práticas e os valores alimentares culturalmente referenciados, bem como estimular a produção e o consumo de alimentos saudáveis, sempre levando em consideração os aspectos comportamentais e afetivos relacionados às práticas alimentares (BRASIL, 2005).

\section{Considerações Finais}

Diante do exposto verificou-se a necessidade de maior incentivo na produção de alimentos regionais, sobretudo no período de estiagem, onde o leque de alimentos ofertados é menor. O incentivo ao plantio irrigado com assistência técnica aos agricultores pode ser uma saída para a diversificação de alimentos durante todo ano, amenizando o problema de sazonalidade da disponibilidade de gêneros alimentícios.

Dada a importância do PNAE como estratégia de promoção de saúde no ambiente escolar, sugere-se a promoção de um debate ampliado sobre as possibilidades educativas que se colocam a partir da relação da agricultura familiar com a alimentação escolar, visando à promoção da saúde da comunidade escolar como um todo, reuniões periódicas realizadas pelas entidades executoras e programas em parceria com a secretaria de agricultura dos municípios.

Para efeito mais consolidado da participação da agricultura familiar no PNAE, se faz necessário uma melhor conscientização da sociedade e de seus dirigentes sobre a importância dessa agricultura dentro do contexto da alimentação do escolar e seus efeitos positivos sobre a saúde.

Dar apoio ao desenvolvimento da agricultura familiar e empreendedores familiares rurais é antes de tudo melhorar as condições sociais do país, promovendo oportunidade a esses produtores de se inserirem no mercado, diminuindo o êxodo rural, aumentando a produção de alimentos, gerando emprego e renda.

\section{Referências}

AROUCHA. E.P.T.L. Agricultura Familiar na Alimentação Escolar: Estudo de oportunidades e de desafios. 2012. 182f. Dissertação apresentada ao Programa de PósGraduação em Ecologia Humana e Gestão Socioambiental (PPGEcoH) da Universidade do Estado da Bahia, Campus VIII, como requisito parcial para obtenção de título de Mestre em Ecologia Humana e Gestão Socioambiental Paulo Afonso/BA, março, 2012. 
BRASIL (a), MINISTÉRIO DA EDUCAÇÃO. FNDE. Brasília, 2009. Lei no 11.947, de 16/6/2009. Disponível em: <http://www.fnde.gov.br/programas/alimentacaoescolar/alimentacao-escolar-apresentacao>. Acessado em: 2 de Out. 2015.

BRASIL (b). Ministério da Educação. Fundo Nacional de desenvolvimento da educação. Resolução/CD/FNDE No38, de 16 de julho de 2009, 2009.

BRASIL. Ministério da Saúde. Guia alimentar para a população brasileira. Brasília, 2005.

BRASIL. Resolução No 466, de 12 de dezembro 2012. Disponível em: < http://conselho.saude.gov.br/resolucoes/2012/Reso466.pdf> Acessado em: 04 de Jan. de 2016.

CHAVES, L.G.; MENDES, P.N.R.; BRITTO, R.R.; BOTELHO, R.B.A. O programa nacional de alimentação escolar como promotor de hábitos alimentares regionais. Revista de Nutrição, v.22, n.6, p.857-866, 2009.

FLÁVIO, E.F.; BARCELOS, M.F.P.; CIRILLO, M.A.; RIBEIRO, A.H. Avaliação da alimentação escolar oferecida aos alunos dos alunos do ensino fundamental das escolas municipais de Lavras, MG. Revista Ciência e Agrotecnologia, v.32, n.6, p.1879-1887, 2008.

FNDE (a), MINISTÉRIO DA EDUCAÇÃO. FNDE. Brasília. Alimentação escolar e Agricultura Familiar. Disponível em:〈www.fnde.gov.br/pnae >. Acessado em: 14 de Ago. de 2017.

FNDE (b), MINISTÉRIO DA EDUCAÇÃO. FNDE. Brasília. Alunado Por Ação Do Programa Nacional De Alimentação Escolar Disponível em:< www.fnde.gov.br/pnaeweb/publico/relatorioDelegacaoEstadual.do>. Acessado em: 14 de Ago. de 2017.

FNDE, MINISTÉRIO DA EDUCAÇÃO. FNDE. Brasília. Artigo 36 da Resolução CD/FNDE $n^{\circ}$ 38, de 16 de julho de 2009. Disponível em :< www.fnde.gov.br/arquivos/category/60-2012download=57>. Acessado em: 11 de Nov. de 2015.

INSTITUTO BRASILEIRO DE GEOGRAFIA E ESTATÍSTICA (IBGE). Pesquisa de Orçamentos Familiares 2008-2009: análise do consumo alimentar pessoal no Brasil. Rio de Janeiro: Instituto Brasileiro de Geografia e Estatística; 2010.

KAGEYAMA, A.; HOFFMANN, R. Pobreza, segurança alimentar e saúde no Brasil. Campinas: Fundação Economia de Campinas, 2007.

RESENDE G.M; BORGES R.M.E; GONÇALVES N.P.S. Produtividade da cultura da abóbora em diferentes densidades de plantio no Vale do São Francisco. Horticultura Brasileira. v. 31, n. 3, p.504-508, 2013.

RODRIGUES, R. et al. A aquisição de alimentos da agricultura familiar pelo PNAE no município de Alegre-ES. Demetra. v. 12, n. 1, p.91-112, 2017. DOI:

10.12957/demetra.2017.26701 